\title{
Balkanologie
}

Balkanologie Revue d'études pluridisciplinaires

Vol. III, n² | 1999

Volume III Numéro 2

\section{Pavlowitch (Stevan K.), A History of the Balkans,} 1804-1945

London / New York : Longman, 1999, 375 p.

\section{Bernard Lory}

\section{OpenEdition}

\section{Journals}

Édition électronique

URL : http://journals.openedition.org/balkanologie/2190

DOI : 10.4000/balkanologie.2190

ISSN : 1965-0582

\section{Éditeur}

Association française d'études sur les Balkans (Afebalk)

Édition imprimée

Date de publication : 1 décembre 1999

ISSN : 1279-7952

\section{Référence électronique}

Bernard Lory, «Pavlowitch (Stevan K.), A History of the Balkans, 1804-1945 », Balkanologie [En ligne],

Vol. III, n² | 1999, mis en ligne le 22 juin 2010, consulté le 17 décembre 2020. URL : http://

journals.openedition.org/balkanologie/2190; DOI : https://doi.org/10.4000/balkanologie.2190

Ce document a été généré automatiquement le 17 décembre 2020.

(c) Tous droits réservés 


\section{Pavlowitch (Stevan K.), A History of the Balkans, 1804-1945}

London / New York : Longman, 1999, 375 p.

\section{Bernard Lory}

\section{RÉFÉRENCE}

Pavlowitch (Stevan K.), A History of the Balkans, 1804-1945, London / New York :

Longman, 1999, $375 \mathrm{p}$.

1 On ne peut que saluer la parution de cet ouvrage de synthèse, clair et précis, qui couvre une période cruciale de l'histoire balkanique. Destiné en premier lieu à un public d'étudiants, il s'inscrit directement dans la lignée des ouvrages de Stavrianos et Jelavich, ou bien, hors de la sphère anglo-saxonne, de ceux de Hösch ou de Castellan ${ }^{1}$. En choisissant de ne couvrir un laps que d'un siècle et demi, l'auteur fait preuve de sagesse et d'efficacité. Si l'histoire balkanique ne se comprend bien que dans une approche longue, les ouvrages que nous venons de mentionner pèchent souvent, par une avalanche de noms et de faits, d'un effet décourageant pour le lecteur averti.

Guidé par un souci pédagogique constant, l'ouvrage est sans surprise dans sa structure : quinze chapitres chronologiques, scandés par les grands événements militaires et diplomatiques, consacrant la moitié de l'ouvrage aux années 1900-1945. L'exposé est segmenté en fonction des États ou des groupes nationaux, ce qui constitue une des contraintes incontournables pour toute histoire de la zone, mais l'auteur s'applique à souligner les traits communs à des évolutions le plus souvent parallèles. On note aussi son souci d'intégrer une histoire économique, souvent trop négligée, non seulement comme arrière-plan, mais comme moteur explicatif: elle permet de relativiser les flamboyances théâtrales (tragédie antique ou opérette viennoise) trop souvent associées à l'histoire balkanique, en problématisant la difficile insertion d'une région périphérique dans le développement industriel européen. 
3 On peut regretter la cartographie très rudimentaire, qui n'apporte aucun soutien au lecteur.

4 Il faut en revanche souligner l'intérêt de la conclusion où Stevan Pavlowitch quitte le ton académique, froid et distancié, pour une prise de position plus personnelle particulièrement stimulante. Comment aborder l'histoire balkanique entre les récits nationalistes exaltés et la vision occidentale minorisante? En quelques pages vigoureuses, il déblaie des mètres cubes de préjugés et d'incompréhension (pp. 331-337) et propose un heureux antidote à ceux qu'afflige la sinistrose balkanique !

\section{NOTES}

1. Stavrianos (L. S.), The Balkans since 1453, New York, 1958 ; Jelavich (Barbara), History of the Balkans, 2 vol., Cambridge, 1983 ; Hösch (E.), Geschichte der Balkanhalbinsel von der Frühzeit bis zur Gegenwart, München, 1988 ; Castellan (Georges), Histoire des Balkans, XV-XX siècles, Paris, 1991 (édition revue et complétée, Paris, 1999).

\section{AUTEURS}

BERNARD LORY 